\title{
Computed Tomography for the Diagnosis and Evaluation of the Severity of Community-acquired Pneumonia in the Elderly
}

\author{
Takahiro Haga $^{1,2}$, Mizuki Fukuoka ${ }^{1,2}$, Mizuo Morita ${ }^{1}$, Kohei Cho ${ }^{1}$ and Koichiro Tatsumi ${ }^{2}$
}

\begin{abstract}
Objective We herein assessed the utility of computed tomography (CT) for the diagnosis and ascertainment of the severity of community-acquired pneumonia (CAP) in the elderly.

Methods The utility of CT compared with chest radiography (CR) for the diagnosis of CAP was prospectively studied among elderly inpatients with clinical symptoms and signs indicative of CAP at the Department of Respiratory Medicine in Nissan Tamagawa Hospital during the one-year period from January 2013 to December 2013. Additionally, we evaluated whether the findings of CT were useful as predictive factors related to the mortality rate associated with CAP.

Results One hundred and forty-two patients, 65 years of age or older, were surveyed upon hospital admission for suspected CAP. Of the 142 patients included, 127 (89.4\%) had pneumonic infiltration diagnosed by CT, however, CR could not recognize pneumonic infiltration in $9.4 \%(12 / 127)$ of these patients. In 127 CAPpositive patients, bilateral pneumonic infiltration was more frequently detected by $\mathrm{CT}$ in non-survivors than survivors $(79.0 \%$ vs. $53.7 \%$; $\mathrm{p}<0.05)$. By a multivariable analysis to determine the prognostic factors related to mortality from CAP, oxygen desaturation showed the greatest odds ratio among the other predictive factors, followed by comorbid neoplastic disease, blood urea nitrogen $\geq 21 \mathrm{mg} / \mathrm{dL}$, male gender, and bilateral pneumonic infiltration diagnosed by CT.
\end{abstract}

Conclusion We herein demonstrated that $\mathrm{CT}$ was superior to $\mathrm{CR}$ for diagnosing and evaluating the severity of CAP in elderly patients.

Key words: computed tomography, chest radiography, community-acquired pneumonia, pneumonia, elderly

(Intern Med 55: 437-441, 2016)

(DOI: 10.2169/internalmedicine.55.5556)

\section{Introduction}

Pneumonia is the leading cause of infectious death and the fourth greatest source of overall mortality in the elderly (1). The presence of underlying comorbid diseases, an impaired mucociliary clearance, and waning immunity contribute to the increased incidence of pneumonia in the elderly $(2,3)$. Advanced age itself is ascribed as the main factor that predisposes the elderly to the high incidence of and mortality from community-acquired pneumonia (CAP) $(4,5)$.
In this context, a radiographic evaluation of CAP plays an important role for the following appraisals (6): 1) diagnosis, 2) evaluation of disease severity, 3) determination of therapeutic effect, 4) presumption of causal organism, and 5) differentiation of contributory diseases other than CAP. However, only one previous study has shown the diagnostic superiority of computed tomography (CT) in comparison to chest radiography (CR) for CAP. Syrjälä et al. reported that 26/47 (55.3\%) patients with signs and symptoms indicative of CAP showed pneumonic infiltration by CT. Yet, that pneumonic infiltration was not detected in $\mathrm{CR}$ films of $30.8 \%(8 / 26)$ of those patients (7). Thus, for the manage-

${ }^{1}$ Division of Respiratory Medicine, Nissan Tamagawa Hospital, Japan and ${ }^{2}$ Department of Respirology, Graduate School of Medicine, Chiba University, Japan

Received for publication April 10, 2015; Accepted for publication May 12, 2015

Correspondence to Dr. Takahiro Haga, tknhosp@yahoo.co.jp 
ment of CAP, the use of CT apparently provides improved diagnostic accuracy compared with CR. Nevertheless, controversy remains regarding the benefit of CT for diagnostic purposes in general and the radiation risk in particular. Considering the prevalence of and high mortality rate from CAP in the elderly (1), further evidence regarding the benefits of CT is well-warranted.

To the best of our knowledge, no report has so far documented the usefulness of CT for evaluating the severity of CAP. Multilobar pneumonic infiltration and bilateral pleural effusion revealed by $\mathrm{CR}$ were confirmed to be prognostic factors related to death from $\operatorname{CAP}(8,9)$. Considering the diagnostic superiority of CT to CR in patients with CAP, we speculate that $\mathrm{CT}$ is also superior for categorizing the severity of this disease. Therefore, this study was designed to evaluate the usefulness of CT for diagnosing CAP and establishing its severity in elderly patients.

\section{Materials and Methods}

\section{Data collection}

The utility of CT compared with CR for the diagnosis of CAP was prospectively studied among elderly inpatients with clinical symptoms and signs indicative of CAP at the Department of Respiratory Medicine in Nissan Tamagawa Hospital during the one-year period from January 2013 to December 2013. Additionally, we evaluated whether the findings of CT were useful as predictive factors related to the mortality rate associated with CAP. This study was approved by the institutional review board of Nissan Tamagawa Hospital. Written informed consent from all patients or their legal proxies was obtained.

CR and CT scans were obtained at the time of admission from all elderly patients ( $\geq 65$ years of age) who had been admitted to our department with clinical indicators of CAP (e.g., cough, a fever, productive sputum, dyspnea, chest pain and abnormal breath sounds). We recorded each patient's physical characteristics, clinical parameters and laboratory findings on admission. Sputum was obtained from all the patients before antibiotics administration and cultured to detect respiratory pathogens. Outcomes were tracked as either life or death at the time of hospital discharge. CRs were obtained with the use of a digital Fuji FCR 9501 unit (Fuji, Tokyo, Japan) with $140 \mathrm{kV}$ tube voltage and a 1.8 or $2 \mathrm{~m}$ image receptor distance. Posterior-anterior views were routinely obtained. When a posterior-anterior view was not available, an anterior-posterior view was substituted. For sequential CT scans, we used a 64-detector-row CT scanner (Aquilion-64; Toshiba Medical, Tokyo, Japan) with a 2-mm slice thickness, scanning parameters of $120 \mathrm{kVp}, 150 \mathrm{mAs}$ and a field of view of $32 \mathrm{~cm}$. Two faculty members belonging to the Department of Respiratory Medicine (T. H. and M. F.), who were familiar with the methods for both CR and CT, evaluated the images individually while blinded to each other's opinions. Thereafter, they reached a consensus decision to determine whether each patient had pneumonic infiltration and/or pleural effusion and whether these findings were unilateral or bilateral.

Our criterion for the diagnosis of CAP was whether pneumonic infiltration was detected or not. That is, all patients diagnosed with CAP were, by definition, those with pneumonic infiltration detectable by CT. Next, age, gender, the comorbidities, clinical parameters, laboratory results, isolated respiratory pathogens, and radiologic findings were compared between two patient groups, those living at the time of hospital discharge or expired, to assess whether CT was useful for evaluating the severity of CAP. A multivariate analysis determined which prognostic factors were related to mortality from CAP. After we identified bilateral pneumonic infiltration as a prognostic factor related to mortality, we compared the clinical data from patients with bilateral pneumonic infiltration to those with unilateral pneumonic infiltration detectable by CT to determine the factors specific for bilateral pneumonic infiltration.

\section{Statistical analysis}

The quantitative data are presented as the means \pm SD. Kappa statistics, a measure of inter-observer reliability that adjusts for random agreement, were used to assess the statistical significance of agreement between faculties. The differences between survivors and non-survivors and between patients with bilateral pneumonic infiltration detectable by CT and those with unilateral pneumonic infiltration were calculated using the Chi-square test for categorical variables and Student's $t$-test for quantitative variables. A multiple logistic regression analysis was subsequently used to assess the role of several variables as prognostic factors related to mortality from CAP. A value of $\mathrm{p}<0.05$ was considered to be significant. A statistical software package (JMP, version 10.0.2; SAS Institute; Cary, USA) was used for the statistical analysis.

\section{Results}

A total of 142 elderly patients who demonstrated clinical symptoms and signs of CAP upon hospital admission were included in this study during a one-year study period. Among them, 127 (89.4\%) were diagnosed with CAP when presenting with pneumonic infiltration on $\mathrm{CT}$ scans. One hundred-fifteen $(90.6 \%)$ of the 127 patients had pneumonic infiltration diagnosed by $\mathrm{CR}$; however, no pneumonic infiltration was diagnosed by $\mathrm{CR}$ in $9.4 \%(12 / 127)$ of the patients. Posterior-anterior views were obtained in $32(25.2 \%)$ of 127 patients; otherwise, anterior-posterior views were substituted. However, the diagnostic accuracy of these views did not differ significantly. The level of agreement between the two faculties, according to the kappa values, was 0.74 for pneumonic infiltration by CR, 0.94 for pleural effusion by $\mathrm{CR}, 0.82$ for pneumonic infiltration by $\mathrm{CT}$, and 0.90 for pleural effusion by CT.

The characteristics of CAP patients according to the sur- 
Table 1. Characteristics of 127 Patients with CAP according to the Outcome*.

\begin{tabular}{|c|c|c|c|}
\hline & $\begin{array}{l}\text { Survivors } \\
(\mathrm{n}=108)\end{array}$ & $\begin{array}{c}\text { Non-survivors } \\
\quad(\mathrm{n}=19)\end{array}$ & $\mathrm{p}$ value \\
\hline Age (years old) (range) & $\begin{array}{l}84.5 \pm 9.2 \\
(66-108)\end{array}$ & $\begin{array}{c}86.8 \pm 5.6 \\
(74-95)\end{array}$ & 0.279 \\
\hline Male / female & $58 / 50$ & $15 / 4$ & $<0.05$ \\
\hline \multicolumn{4}{|l|}{ Comorbidities } \\
\hline Neoplastic disease & $4(3.7 \%)$ & $4(21.1 \%)$ & $<0.01$ \\
\hline Congestive heart failure & $15(13.9 \%)$ & $4(21.1 \%)$ & 0.420 \\
\hline Chronic renal disease & $11(10.2 \%)$ & $3(15.8 \%)$ & 0.472 \\
\hline Chronic liver disease & $2(1.9 \%)$ & $0(0 \%)$ & 0.550 \\
\hline \multicolumn{4}{|l|}{ Clinical parameters } \\
\hline Orientation disturbance (confusion) & $12(11.1 \%)$ & $5(26.3 \%)$ & 0.073 \\
\hline $\begin{array}{l}\text { Systolic } \mathrm{BP}<90 \mathrm{~mm} \mathrm{Hg} \text { or } \\
\text { diastolic } \mathrm{BP} \leq 60 \mathrm{mmHg}\end{array}$ & $2(1.9 \%)$ & $2(10.5 \%)$ & 0.064 \\
\hline \multicolumn{3}{|l|}{ Laboratory findings } & $<0.001$ \\
\hline Blood urea nitrogen, $\mathrm{mg} / \mathrm{dL}$ & $21.8 \pm 11.8$ & $33.1 \pm 17.5$ & $<0.001$ \\
\hline Albumin, $\mathrm{g} / \mathrm{dL}$ & $3.3 \pm 0.5$ & $3.0 \pm 1.1$ & 0.181 \\
\hline $\mathrm{C}$-reactive protein, $\mathrm{mg} / \mathrm{dL}$ & $8.0 \pm 7.1$ & $9.8 \pm 9.0$ & 0.200 \\
\hline \multicolumn{4}{|l|}{ Isolated microorganisms } \\
\hline Staphylococcus aureus & $30(27.8 \%)$ & $6(31.6 \%)$ & 0.735 \\
\hline Methicillin-sensitive & $10(9.3 \%)$ & $3(15.8 \%)$ & 0.387 \\
\hline Methicillin-resistant & $20(18.5 \%)$ & $3(15.8 \%)$ & 0.776 \\
\hline Streptococcus pneumonia & $5(4.6 \%)$ & $0(0 \%)$ & 0.339 \\
\hline Other Gram-positive bacteria & $4(3.7 \%)$ & $1(5.3 \%)$ & 0.747 \\
\hline Klebsiella pneumonia & $16(14.8 \%)$ & $3(15.8 \%)$ & 0.913 \\
\hline Pseudomonas aeruginosa & $16(14.8 \%)$ & $4(21.1 \%)$ & 0.491 \\
\hline Haemophilus influenza & $6(5.6 \%)$ & $1(5.3 \%)$ & 0.959 \\
\hline Escherichia coli & $5(4.6 \%)$ & $0(0 \%)$ & 0.339 \\
\hline Other Gram-negative bacteria & $10(9.3 \%)$ & $1(5.3 \%)$ & 0.568 \\
\hline Normal flora & $24(22.2 \%)$ & $5(26.3 \%)$ & 0.695 \\
\hline
\end{tabular}

vival or fatal outcome are summarized in Table 1. These features of the non-survivors differed distinctly from those of the survivors. The non-survivors' group was predominantly male and highly associated with neoplastic disease. A greater prevalence of oxygen desaturation was noted in this group, and the serum level of blood urea nitrogen was statistically higher. The distribution of isolated respiratory pathogens did not differ significantly between the two groups.

The radiographic findings were then compared between the two groups (Table 2). Bilateral pneumonic infiltration was more frequently diagnosed by $\mathrm{CT}$ in the non-survivors than in the survivors $(79.0 \%$ vs. $53.7 \%$; $\mathrm{p}<0.05)$.

To identify the prognostic factors related to mortality, we performed a multivariate analysis (Table 3). Oxygen desaturation showed the greatest odds ratio among the other predictive factors, followed by comorbid neoplastic disease, blood urea nitrogen levels $\geq 21 \mathrm{mg} / \mathrm{dL}$, male gender, and bilateral pneumonic infiltration diagnosed by CT.

Next, we compared the clinical data of patients with bilateral pneumonic infiltration detectable by $\mathrm{CT}$ and those with unilateral pneumonic infiltration (Table 4). Low serum levels of albumin and high serum levels of C-reactive protein were related to bilateral pneumonic infiltration.
Table 2. Radiographic Findings of 127 Patients with CAP according to the Outcome.

\begin{tabular}{lccc}
\hline & $\begin{array}{c}\text { Survivors } \\
\mathrm{n}=108(\%)\end{array}$ & $\begin{array}{c}\text { Non-survivors } \\
\mathrm{n}=19(\%)\end{array}$ & $\mathrm{p}$ value \\
\hline $\begin{array}{l}\text { Diagnosed by CR } \\
\text { Bilateral pneumonic infiltration }\end{array}$ & $30(27.8)$ & $8(42.1)$ & 0.209 \\
$\begin{array}{l}\text { Bilateral pleural effusion } \\
\text { Diagnosed by CT }\end{array}$ & $8(7.4)$ & $3(15.8)$ & 0.231 \\
Bilateral pneumonic infiltration & $58(53.7)$ & $15(79.0)$ & $<0.05$ \\
Bilateral pleural effusion & $18(16.7)$ & $6(31.6)$ & 0.126 \\
\hline
\end{tabular}

CR: chest radiography, CT: computed tomography

\section{Discussion}

This study demonstrated that $9.4 \%$ of elderly patients with CAP confirmed by CT may have been diagnosed incorrectly if only taking the CR findings into account. Furthermore, bilateral pneumonic infiltration clearly evident on the CT scans was an independent prognostic factor related to the deaths of elderly patients with CAP. No CR results provided a statistically significant prognostic factor. Thus, CT was superior to CR for not only the diagnosis, but also defining the severity of CAP in the elderly.

The superiority of CT to $\mathrm{CR}$ for related diagnoses was previously shown in patients with diffuse infiltrative lung disease (10) and severe acute respiratory syndrome (SARS) (11-13). The reported sensitivity of CT for the diagnosis of SARS was $100 \%$, whereas that of CR was only $57.5-66.7 \%$ (11-13). Several reasons have been proposed for overlooking pneumonic infiltration on CR films: 1) the shadow is localized and/or too light (11);2) anatomic structures, such as the diaphragm and heart, may be superimposed so as to impair the diagnostic accuracy of CR (12); 3) the anterior-posterior view is less diagnostically accurate than the posterior-anterior view. Seven $(58.3 \%)$ of $12 \mathrm{CR}$ misdiagnosed patients had pneumonic infiltration superimposed by the diaphragm in this study.

Only one previous study, a report by Syrjälä et al., has suggested the diagnostic utility of CT in CAP patients (7). They reported that $30.8 \%$ of pneumonic infiltrations visible by CT were not detectable by CR, whereas only $9.4 \%$ of them were not visible by $\mathrm{CR}$ in our results. The differences between our results may be because all our patients were hospitalized during the present study, whereas only $40.4 \%$ of the group they studied were inpatients. The severity of disease in the two patient populations may have differed as well.

The utility of CT for categorizing the severity of CAP patients has not been reported previously. However, several reports have linked specific prognostic factors identified by CR to mortality from $\operatorname{CAP}(8,9,14,15)$. A previous metaanalysis revealed that multilobar pneumonic infiltration was an independent prognostic factor of CAP-related deaths (odds ratio $=3.1$ ) (14). Moreover, a multivariate analysis of a prospective cohort study identified bilateral pleural effusion as an independent prognostic factor of fatal CAP (relative 
Table 3. Prognostic Factors Related to Mortality according to a Logistic Regression Analysis.

\begin{tabular}{lccc}
\hline \multicolumn{1}{c}{ Risk factors } & Odds ratio & $95 \%$ CI & p value \\
\hline $\mathrm{SpO}_{2} \leq 90 \%$ while breathing room air & 8.6 & $1.1-67.3$ & $<0.01$ \\
Neoplastic disease & 6.9 & $1.5-30.7$ & $<0.05$ \\
Blood urea nitrogen $\geq 21 \mathrm{mg} / \mathrm{dL}$ & 5.2 & $1.8-14.7$ & $<0.01$ \\
Male & 4.4 & $1.2-16.1$ & $<0.05$ \\
Bilateral pneumonic infiltration diagnosed by computed tomography & 3.2 & $1.0-10.4$ & $<0.05$ \\
\hline $\mathrm{SpO}_{2}$ : oxygen saturation measured by pulse oximetry, CI: confidence interval & & &
\end{tabular}

Table 4. Characteristics of 127 Patients with CAP according to the Distribution of Pneumonic Infiltration Detectable by CT*.

\begin{tabular}{|c|c|c|c|}
\hline & $\begin{array}{r}\text { Bilateral } \\
(\mathrm{n}=73)\end{array}$ & $\begin{array}{c}\text { Unilateral } \\
(\mathrm{n}=54)\end{array}$ & $\mathrm{p}$ value \\
\hline Age (years old) (range) & $\begin{array}{c}84.5 \pm 8.2 \\
(74-95)\end{array}$ & $\begin{array}{l}85.3 \pm 6.6 \\
(66-108)\end{array}$ & 0.422 \\
\hline Male / female & $40 / 33$ & $33 / 21$ & 0.477 \\
\hline \multicolumn{4}{|l|}{ Comorbidities } \\
\hline Neoplastic disease & $4(5.5 \%)$ & $4(7.4 \%)$ & 0.659 \\
\hline Congestive heart failure & $13(17.8 \%)$ & $6(11.1 \%)$ & 0.296 \\
\hline Chronic renal disease & $10(13.7 \%)$ & $4(7.4 \%)$ & 0.263 \\
\hline Chronic liver disease & $2(2.7 \%)$ & $0(0 \%)$ & 0.220 \\
\hline \multicolumn{4}{|l|}{ Clinical parameters } \\
\hline Orientation disturbance (confusion) & $10(13.7 \%)$ & $7(13.0 \%)$ & 0.263 \\
\hline \multicolumn{4}{|l|}{ Systolic BP $<90 \mathrm{~mm} \mathrm{Hg}$ or diastolic } \\
\hline $\mathrm{BP} \leq 60 \mathrm{mmHg}$ & $2(2.7 \%)$ & $2(3.7 \%)$ & 0.220 \\
\hline $\mathrm{SpO}_{2} \leq 90 \%$ while breathing room air & $21(28.8 \%)$ & $13(24.1 \%)$ & 0.555 \\
\hline \multicolumn{4}{|l|}{ Laboratory findings } \\
\hline Blood urea nitrogen, $\mathrm{mg} / \mathrm{dL}$ & $22.9 \pm 10.6$ & $24.3 \pm 10.5$ & 0.688 \\
\hline Albumin, $\mathrm{g} / \mathrm{dL}$ & $2.8 \pm 0.7$ & $3.9 \pm 0.6$ & $<0.05$ \\
\hline C-reactive protein, $\mathrm{mg} / \mathrm{dL}$ & $9.9 \pm 5.8$ & $8.0 \pm 5.1$ & $<0.05$ \\
\hline \multicolumn{4}{|l|}{ Isolated microorganisms } \\
\hline Staphylococcus aureus & $18(24.7 \%)$ & $18(33.3 \%)$ & 0.284 \\
\hline Methicillin-sensitive & $7(9.6 \%)$ & $6(11.1 \%)$ & 0.780 \\
\hline Methicillin-resistant & $11(15.1 \%)$ & $12(22.2 \%)$ & 0.301 \\
\hline Streptococcus pneumonia & $3(4.1 \%)$ & $2(3.7 \%)$ & 0.907 \\
\hline Other Gram-positive bacteria & $3(4.1 \%)$ & $2(3.7 \%)$ & 0.907 \\
\hline Klebsiella pneumonia & $12(16.4 \%)$ & $7(13.0 \%)$ & 0.587 \\
\hline Pseudomonas aeruginosa & $10(13.7 \%)$ & $10(18.5 \%)$ & 0.461 \\
\hline Haemophilus influenza & $3(4.1 \%)$ & $4(7.4 \%)$ & 0.421 \\
\hline Escherichia coli & $2(2.7 \%)$ & $3(5.6 \%)$ & 0.420 \\
\hline Other Gram-negative bacteria & $5(6.8 \%)$ & $6(11.1 \%)$ & 0.399 \\
\hline Normal flora & $19(26.0 \%)$ & $10(18.5 \%)$ & 0.319 \\
\hline
\end{tabular}

risk $=2.8$ ) (15). In the present study, bilateral pneumonic infiltration along with bilateral pleural effusion were factors detected more often by $\mathrm{CR}$ in the non-survivors than in the survivors $(42.1 \%$ vs. $27.8 \%$; $=0.209$ and $15.8 \%$ vs. $7.4 \%$; $\mathrm{p}=0.231$, respectively) (Table 2). Because the relatively small size of our study may account for the lack of a statistically significant difference, future investigation of a larger population is appropriate.

In the present study, bilateral pneumonic infiltration detectable by $\mathrm{CT}$ was related to low serum levels of albumin and high serum levels of C-reactive protein. Hypoalbuminemia may lead to capillary leakage. Furthermore, the elevation of C-reactive protein may represent intense systemic inflamation, which could promote vascular permeability. There may also be causal relationships between these two factors and bilateral pneumonic infiltration.

If the superiority of CT to CR for the diagnosis and severity scoring of CAP in the elderly is confirmed, then the radiation risk may be the most important limiting factor for the evaluation of CAP by CT $(16,17)$. The benefit of early antibiotic therapy in patients presenting with severe infections has been recognized $(6,18)$, and we agree. Therefore, an accurate diagnosis and evaluation of severity by CT may warrant the risk of radiation and signal the need for early antibiotic therapy, thereby improving the outcome of CAP in elderly patients, as further investigation is likely to support.

There are several limitations associated with the present study. First, this study was conducted at a single medical institution. The clinical features of the patients enrolled in this study may not be generalized to patients treated elsewhere. Therefore, a multicenter clinical trial with varied practice styles and therapeutic approaches for CAP is needed to confirm the present findings. Second, because only inpatients were enrolled in this study, our findings may not be generalized to outpatients. Finally, we evaluated the radiographic findings to determine only whether pneumonic infiltration and pleural effusion were present or not and were located unilaterally or bilaterally. Detailed evaluations of pneumonic infiltration may be needed to confirm the present evidence that CT is the favorable option for evaluating CAP of the elderly.

In conclusion, we herein demonstrated that CT was superior to $\mathrm{CR}$ for the diagnosis and evaluation of severity in CAP of the elderly. This study provides a good basis for continued investigation of CT as a means of improving the evaluation of CAP in the elderly.

The authors state that they have no Conflict of Interest (COI).

\section{References}

1. Ochoa-Gondar O, Vila-Córcoles A, de Diego C, et al. The burden of community-acquired pneumonia in the elderly: the Spanish EVAN-65 study. BMC Public Health 8: 222, 2008.

2. Meltzer MI. Increased hospitalizations of elderly patients. Emerg Infect Dis 14: 847-848, 2008.

3. Trotter CL, Stuart JM, George R, Miller E. Increasing hospital admissions for pneumonia, England. Emerg Infect Dis 14: 727-733, 2008.

4. Yu H, Rubin J, Dunning S, Li S, Sato R. Clinical and economic burden of community-acquired pneumonia in the Medicare feefor-service population. J Am Geriatr Soc 60: 2137-2143, 2012. 
5. Musgrave T, Verghese A. Clinical features of pneumonia in the elderly. Semin Respir Infect 5: 269-275, 1990.

6. Mandell LA, Wunderink RG, Anzueto A, et al. Infectious Diseases Society of America/American Thoracic Society consensus guidelines on the management of community-acquired pneumonia in adults. Clin Infect Dis 44: S27-S72, 2007.

7. Syrjälä H, Broas M, Suramo I, Ojala A, Lähde S. High-resolution computed tomography for the diagnosis of community-acquired pneumonia. Clin Infect Dis 27: 358-363, 1998.

8. Paganin F, Lilienthal F, Bourdin A, et al. Severe communityacquired pneumonia: assessment of microbial aetiology as mortality factor. Eur Respir J 24: 779-785, 2004.

9. Mortensen EM, Coley CM, Singer DE, et al. Causes of death for patients with community-acquired pneumonia: results from the Pneumonia Patient Outcomes Research Team cohort study. Arch Intern Med 162: 1059-1064, 2002.

10. Swensen SJ, Aughenbaugh GL, Myers JL. Diffuse lung disease: diagnostic accuracy of CT in patients undergoing surgical biopsy of the lung. Radiology 205: 229-234, 1997.

11. Wong KT, Antonio GE, Hui DS, et al. Thin-section CT of severe acute respiratory syndrome: evaluation of 73 patients exposed to or with the disease. Radiology 228: 395-400, 2003.
12. Hui JY, Hon TY, Yang MK, et al. High-resolution computed tomography is useful for early diagnosis of severe acute respiratory syndrome-associated coronavirus pneumonia in patients with normal chest radiographs. J Comput Assist Tomogr 28: 1-9, 2004.

13. Zhao D, Ma D, Wang W, et al. Early X-ray and CT appearances of severe acute respiratory syndrome: an analysis of 28 cases. Chin Med J (Engl) 116: 823-826, 2003.

14. Fine MJ, Smith MA, Carson CA, et al. Prognosis and outcomes of patients with community-acquired pneumonia. A meta-analysis. JAMA 275: 134-141, 1996.

15. Hasley $\mathrm{PB}$, Albaum $\mathrm{MN}$, Li $\mathrm{YH}$, et al. Do pulmonary radiographic findings at presentation predict mortality in patients with community-acquired pneumonia? Arch Intern Med 156: 22062212, 1996.

16. DiMarco AF, Briones B. Is chest CT performed too often? Chest 103: 985-986, 1993.

17. Naidich DP, Pizzarello D, Garay SM, Müller NL. Is thoracic CT performed often enough? Chest 106: 331-332, 1994.

18. American Thoracic Society; Infectious Diseases Society of America. Guidelines for the management of adults with hospitalacquired, ventilator-associated, and healthcare-associated pneumonia. Am J Respir Crit Care Med 171: 388-416, 2005.

(C) 2016 The Japanese Society of Internal Medicine http://www.naika.or.jp/imonline/index.html 